\begin{tabular}{|c|c|c|}
\hline $\begin{array}{l}\text { PKS } \\
\text { PUBLIC } \\
\text { KNOWLEDGE } \\
\text { PROJECT }\end{array}$ & $\begin{array}{c}\text { REVISTA DE GEOGRAFIA } \\
\text { (RECIFE) } \\
\text { http://www.revista.ufpe.brr/revistageografia }\end{array}$ & $\begin{array}{l}\text { OJS } \\
\text { OPEN } \\
\text { JOUNAL } \\
\text { SYSTEMT }\end{array}$ \\
\hline
\end{tabular}

\title{
CRISE ESTRUTURAL DO CAPITAL: E O TRABALHO, COMO FICA?
}

\author{
Rafael Rossi ${ }^{1}$ \\ ${ }^{1}$ Docente do curso de Licenciatura em Educação do Campo, do Programa de Pós-Graduação em Ensino de \\ Ciências e da Pós-Graduação em Recursos Naturais da UFMS em Campo Grande - MS. Email: \\ rafaelrossi6789@hotmail.com
}

Artigo recebido em 06/12/2016 e aceito em 13/11/2017

\begin{abstract}
RESUMO
O presente texto conta com uma abordagem da crise atual que enfrenta o sistema do capital a partir das contribuições do filósofo István Mészáros. O objetivo é explicitar o relacionamento do trabalho com a totalidade social e a matriz da crise estrutural deste sistema social. Nosso procedimento, dessa forma, se baseia numa análise de cunho ontológico a partir das contribuições da tradição costumeiramente denominada de ontologia marxiana. A partir disso, explicamos as características mais essenciais desta crise e o desafio que se coloca ao trabalho no sentido de superar este sistema em sua totalidade.
\end{abstract}

Palavras-chave: Crise Estrutural; Trabalho; Capital; Totalidade.

\section{STRUCTURAL CRISIS OF CAPITAL: AND THE LABOUR, HOW IT STAY?}

\begin{abstract}
The present text counts on an approach of the present crisis that faces the system of the capital from the contributions of the philosopher István Mészáros. The objective is to make explicit the relationship of work with the social totality and the matrix of the structural crisis of this social system. Our procedure, therefore, are based on an ontological analysis based on the contributions of the tradition usually called marxian ontology. From this, we explain the most essential characteristics of this crisis and the challenge that it's called to work in order to overcome this system in its entirety.
\end{abstract}

Keywords: Structural Crisis; Labour; Capital; Totality.

\section{INTRODUÇÃO}

Uma discussão imprescindível em ser realizada de modo cada vez mais amplo e persistente, no âmbito da discussão geográfica, diz respeito ao caráter da crise que esta forma de sociabilidade enfrenta. Apesar de muitos discursos e teses defenderem a prerrogativa subjetiva e passageira da presente crise, compreendemos que a raiz de sua manifestação se articula com a maneira como os homens se relacionam entre si no processo de produção das 
condições materiais da existência social no âmbito desta sociedade capitalista. Dessa maneira, para tratarmos - mesmo que brevemente - a respeito da crise estrutural que o capital enfrenta em nosso período histórico, de acordo com Mészáros (1995), algumas reflexões se fazem necessárias em um primeiro momento para entendermos a relação dos complexos sociais entre si.

De acordo com Lukács (2013) a realidade social é composta pela interação dinâmica dos vários complexos sociais entre si, ou seja, ela se consubstancia num "complexo de complexos". Todavia, não se trata de uma totalidade "aérea", isto é, uma totalidade imóvel, ahistórica e inerte. Ao contrário, a totalidade é matrizada por uma determinada forma típica do trabalho. Por isso:

A totalidade consubstanciada pelo ser se manifesta, concretamente, pelas inelimináveis articulações das esferas ontológicas entre si. Já argumentamos que sem o ser inorgânico não há vida, e que sem vida não há ser social: o universo, que é o ser em sua máxima universalidade, é uma totalidade composta por distintos processos que, de uma forma ou de outra, são articulados entre si. (LESSA, 2015, p. 54)

Nesse aspecto, estamos nos referindo ao trabalho enquanto práxis primáriaontológica responsável pela transformação da natureza para a produção dos meios de produção e de subsistência necessários para atender as necessidades humanas. Portanto, não estamos, ainda, nos referindo a uma relação de emprego ou ao trabalho assalariado. $\mathrm{O}$ trabalho, em sentido ontológico, faz com que na reprodução social ocorra incessantemente a produção do novo e não a reposição do mesmo como ocorre no mundo animal. Ou seja:

Em outras palavras, é a capacidade essencial de, pelo trabalho, os homens construírem um ambiente e uma história cada vez mais determinada pelos atos humanos e cada vez menos determinadas pelas leis naturais, que constitui o fundamento ontológico da gênese do ser social. E toda essa processualidade tem, no processo de generalização provocado pelo trabalho, seu momento fundante. (LESSA, 2015, p. 51)

Deste modo, é preciso, em um primeiro momento esclarecer o relacionamento entre trabalho e totalidade e, posteriormente, expor os fundamentos mais gerais da atual crise estrutural do capital. São estes os procedimentos que utilizaremos com intuito de explicitar os aspectos mais gerais que, comumente, são abandonados na maioria das análises contemporâneas da ideologia dominante a respeito da crise que a humanidade enfrenta. É a respeito destas temáticas que trataremos a seguir. 


\section{TOTALIDADE E MOMENTO PREDOMINANTE}

É preciso, logo de início, afirmar que o trabalho é a única categoria que funda o ser social e todas as demais dimensões da vida social. Isto não quer dizer que ele tenha alguma importância moral mais elevada. Afirmar que o trabalho funda o ser social é perceber, na esteira de Marx e Lukács, por exemplo, que os homens distinguem-se dos animais pela sua capacidade de produzir a realidade objetiva social. Tendo por base os elementos da natureza, os homens, por meio do trabalho, conseguem instaurar uma "causalidade posta", isto é, uma série de elementos, instrumentos, objetos, processos e dinâmicas eminentemente sociais e que não surgiriam apenas do movimento espontâneo da natureza, mas sim, tão somente a partir da práxis ontológico-primária que é o trabalho. A respeito disso, afirma Lukács:

Considerando que nos ocupamos do complexo concreto da socialidade como forma de ser, poder-se-ia legitimamente perguntar por que, ao tratar desse complexo, colocamos o acento exatamente no trabalho e lhe atribuímos um lugar tão privilegiado no processo e no salto da gênese do ser social. A resposta, em termos ontológicos, é mais simples do que possa parecer à primeira vista: todas as outras categorias dessa forma de ser têm já, em essência, um caráter puramente social; suas propriedades e seus modos de operar somente se desdobram no ser social já constituído; quaisquer manifestações delas, ainda que sejam muito primitivas, pressupõem o salto como já acontecido. Somente o trabalho tem, como sua essência ontológica, um claro caráter de transição: ele é, essencialmente, uma inter-relação entre homem (sociedade) e natureza, tanto inorgânica (ferramenta, matéria-prima, objeto de trabalho etc.) como orgânica, interrelação que pode figurar em pontos determinados da cadeia a que nos referimos, mas antes de tudo assinala a transição, no homem que trabalha, do ser meramente biológico ao ser social. (LUKÁCS, 2013, p. 43-44, grifos nossos)

A análise de Lukács é clara: apenas o trabalho tem um caráter de transição por estabelecer o intercâmbio orgânico do homem com a natureza com intuito de produzir os bens materiais necessários à vida social. Sobre este aspecto é importante considerar que:

[...] a análise deste ato ontológico-primário, que é o trabalho, revela outros elementos da maior importância para a compreensão da natureza do ser social. Em primeiro lugar, o caráter essencialmente social do homem. Como vimos, o ato do trabalho tem como núcleo mais íntimo a capacidade de generalização. A generalização, por sua vez, começa pela formação de conceitos abstratos capazes de substituir as coisas em sua realidade imediata. Armazenados na consciência e cristalizados nos instrumentos de trabalho, os conceitos permite o seu aproveitamento em novas atividades do mesmo indivíduo e a sua transmissão a outros indivíduos. Deste modo, os poderes individuais se tornam poderes sociais num processo de reprodução cada vez mais ampliado e complexo. É neste sentido que Marx afirma que o homem é um ser genérico e universal, pois o devir do indivíduo não se dá apenas, e nem principalmente, como um desdobramento de leis genéticas, mas implica, sobretudo, a apropriação das objetivações que se tornaram patrimônio do gênero humano. É por isto que Marx afirma que o indivíduo é social por natureza e não porque viva em sociedade. (TONET, 2005, p. 39) 
Todas as outras categorias já terão um caráter profundamente social e, por sua vez, mantêm uma relação de dependência ontológica, determinação recíproca e de autonomia relativa para com o trabalho (TONET, 2005). Assim:

Com o primeiro ato de trabalho, constitui-se o ser social. Já nesse momento ele exibe dois traços ontológicos fundamentais: é unitário e internamente contraditório. Mesmo naquele primeiro ato, o mais simples possível, de troca orgânica do homem com a natureza, já está presente a contradição entre meio e finalidade posta, entre a consciência e o objeto, entre o indivíduo e a totalidade das relações sociais, entre a intentio recta e a intentio obliqua, etc. todavia, os traços de homogeneidade eram obviamente predominantes, dado o baixo grau de desenvolvimento da sociabilidade, a divisão do trabalho, o pouco desenvolvimento das individualidades e a pequena complexidade das relações sociais. (LESSA, 2015, p. 55)

A respeito das interações que são desenvolvidas entre o trabalho e os demais complexos: a dependência ontológica nos permite compreender que todos os complexos "devem" sua existência social ao fato dos seres humanos serem capazes de trabalhar. Mais do que isso: todos os complexos sociais irão ter sua orientação geral a partir das possibilidades efetivas postas pela totalidade. A autonomia relativa nos indica que cada uma das dimensões da existência humana terá uma função distinta e específica no processo de reprodução social. Só cabe ao trabalho, por exemplo, a transformação da natureza na produção dos valores de uso. A determinação recíproca, por sua vez, indica as inúmeras e intrincadas mediações que se estabelecem entre os complexos e com a totalidade.

A totalidade é muito mais do que o trabalho, todavia, ela não poderia existir se não houver esta categoria fundante do ser social. Todos os complexos sociais (filosofia, direito, arte, educação, geografia, política, ciência, ideologia etc.) só podem existir, pois os homens precisam produzir os meios de produção para a existência social. A vida social, dessa forma, é produzia e reproduzida pelos homens - seres humanos - a partir do trabalho e com uma série de outros complexos responsáveis por funções sociais distintas das do trabalho no processo de reprodução social. Isto quer dizer que:

Na medida em que, a partir do trabalho, surgem outros momentos específicos da atividade humana e na medida e que há, entre aquele e estes uma dependência ontológica e uma determinação recíproca, determinação que também existe entre aos diversos momentos, então o ser social se põe, na bela expressão de Lukács, como um complexo de complexos. Quer dizer, ele tem uma matriz ontológica - o trabalho cuja natureza não pode, de modo algum, ser negada, substituída por qualquer outro momento ou entendida em outro sentido que não o ontológico e com ela se articulam todas as outras dimensões sociais. O surgimento de outros campos de atividade a partir do trabalho e o relacionamento entre aqueles e este e deles entre si, implica a existência de uma lógica na entificação do ser social. Lógica esta que nada tem de determinista ou de teleológica, uma vez que a base última do ser social é constituída por atos individuais, nem absolutamente prédeterminados, nem absolutamente livres. (TONET, 2005, p. 41, grifos nossos) 
Com efeito, a totalidade é sempre o momento predominante na orientação geral de todos os complexos sociais. Isto implica entender que, por exemplo, na orientação mais geral do conjunto do complexo social da educação, o momento predominante será exercido pela totalidade social referente àquela forma de sociabilidade. Não é por um acaso qualquer que: "nenhuma interação real (nenhuma real determinação de reflexão) existe sem momento predominante" (LUKÁCS, 2012, p. 333). Com efeito:

Em Lukács, o que distingue o complexo de complexos social da natureza, já vimos, é o fato de ele ter como elemento primário, fundante, atos teleologicamente postos, atos de trabalho. Tais atos, por sua essência, remetem o ser social à criação de necessidades e ao desenvolvimento de meios para a satisfação dessas necessidades, que vão para muito além da esfera de trabalho enquanto tal. Isto, ao mesmo tempo, permite e requer que o ser social desenvolva uma consciência de si próprio que, com o desenvolvimento da sociabilidade, exerce um papel cada vez mais notável no seu desenvolvimento. A humanidade se constitui, por essa via, num complexo de complexos cuja evolução é crescentemente determinada pela consciência que possui de si própria - sem jamais poder prescindir da reprodução biológica que, para sempre, constituirá sua base ineliminável. Em suma, o complexo de complexos, que é o ser social, para Lukács, é muito mais que uma mera totalidade: é uma universalidade potencialmente capaz de conscientemente dirigir sua história. A atualização dessa potencialidade, de forma diferente a cada momento histórico, é o que distingue, para Lukács, o mundo dos homens das esferas naturais. A efetiva construção, ao longo do tempo, da generalidade humana em-si e para-si, é a essência do devir-humano dos homens. A essência humana é a história dos homes. É isso que, essencialmente, distingue, aos olhos de Lukács, o complexo de complexos, que é o ser social, do conjunto dos complexos naturais. (LESSA, 2015, p. 58-59, grifos nossos)

Contudo, com relação à própria totalidade social, o momento predominante será o complexo da economia ${ }^{1}$, por ser aquele responsável pela produção material da existência social. Certamente, a economia, nesse sentido genérico, engloba o trabalho, as forças produtivas e as relações sociais de produção, ou seja, as relações sociais que os homens estabelecem entre si no processo de transformação da natureza. Aliás, como o próprio Marx nos explica: "o modo dessa distribuição será diferente de acordo com o tipo peculiar do próprio organismo social de produção e o correspondente grau histórico de desenvolvimento dos produtores" (MARX, 2013, p. 153, grifos nossos). Desse modo:

É evidente que a produção, enquanto momento predominante, é aqui entendida no sentido mais amplo possível - no sentido ontológico -, como produção e reprodução da vida humana, que até mesmo em seus estágios extremamente primitivos (o pastoreio dos mongóis) vai muito além da mera conservação biológica, não podendo, portanto deixar de ter um acentuado caráter econômico-social. É essa forma geral da produção que determina a distribuição no sentido marxiano. Mais exatamente: o que está em jogo aqui são os homens, cujas capacidades,

\footnotetext{
${ }^{1}$ A esse respeito o trabalho de Andrade (2011) é decisivo para o entendimento destas questões.
} 
hábitos etc. tornam possíveis determinados modos de produção. (LUKÁCS, 2012, p. 336 e 338 , grifos nossos)

O que podemos perceber de toda esta dinâmica? $\mathbf{1}^{\mathbf{o}}$ ) A realidade social não pode ser resumida ao trabalho, porém, só pode existir uma totalidade de complexos sociais, pois os homens transformam a natureza para atender suas necessidades e isso "desperta" dimensões novas com distintas funções no processo de reprodução social; $\mathbf{2}^{\mathbf{0}}$ ) É sempre a totalidade social o momento predominante na orientação de cada complexo social; $\mathbf{3}^{\mathbf{0}}$ ) Perante a própria totalidade é o complexo da economia - aquele responsável pelas condições materiais da existência social - que exercerá o papel de momento predominante e; $\mathbf{4}^{\mathbf{0}}$ ) A distribuição da riqueza socialmente produzida será determinada ontologicamente pelas relações sociais de produção. No caso do capitalismo tais relações sociais de produção se baseiam na desigualdade real entre capital e trabalho, na qual o primeiro subordina todo o processo de trabalho à sua lógica expansionista e incontrolável (MÉSZÁROS, 1995).

\section{CRISE ESTRUTURAL DO CAPITAL E SEUS FUNDAMENTOS ONTOLÓGICOS}

Agora sim, podemos avançar para o entendimento da crise estrutural que o capital enfrenta. Há que se afirmar categoricamente que não há nada de errado em associar o capital a crise. As crises "são maneiras de fazer avançar para além de suas barreiras imediatas" e, com isso, "estender com cruel dinamismo sua esfera de operação e dominação" (MÉSZÁROS, 1995, p. 680). A última coisa, portanto, que interessa ao capital é superar de uma vez por todas as suas crises, por mais que esta seja uma insistência ideológica de seus propagandistas mais tenazes e persistentes.

A matriz "geradora da crise é sempre material e não espiritual" e, dessa forma, que possamos nos contrapor aos discursos de que "o mundo está em crise por causa da perda dos 'verdadeiros' valores tradicionais" (TONET, 2009, p. 125). Afirmar, com efeito, que a matriz da crise encontra respaldo na dimensão material e, mais especificamente, no complexo da economia, não implica nenhum reducionismo mecanicista. Trata-se, sim, em explicitar que "a raiz mais profunda da crise que o mundo vive hoje está nas relações que os homens estabelecem entre si na produção da riqueza material" e, também, que há "uma relação de determinação recíproca entre essa raiz e as outras dimensões da realidade social” (TONET, 2009, p. 125). É decisivo entender que:

Esta forma de sociabilidade tem como seu ato ontológico-primário a compra-evenda da força de trabalho. É a partir deste ato que se originam, em sua forma 
capitalista, o valor de troca, a mercadoria, a propriedade privada, o capital, o trabalho assalariado, a mais-valia, o mercado, etc. A análise marxiana dos mecanismos fundamentais desta sociedade é suficientemente conhecida. O que nos importa ressaltar aqui é o seguinte: Primeiro, o ato de compra-e-venda de força de trabalho é, por sua natureza, um ato gerador de desigualdade social. E isto porque ele opõe indivíduos em situação efetivamente desigual, na medida em que um deles - o capitalista - é proprietário de trabalho acumulado (capital, meios de produção, riqueza, etc.) e o outro - o trabalhador - tem a propriedade apenas da sua força de trabalho. A relação capital/trabalho é, intrinsecamente, uma relação estrutural de subordinação do segundo pelo primeiro. A lógica desta relação implica a reprodução ad infinitum, da desigualdade social. E somente interesses ideológicos ou ignorância podem pretender que o capital, pelo seu próprio movimento interno, possa por fim a este processo. Não é por razões ideológicas nem políticas, mas por razões ontológicas que a reconciliação radical entre trabalho e capital é absolutamente impossível. Neste ato fundante, portanto, já está inscrita a impossibilidade insuperável de constituição de uma autêntica comunidade humana. (TONET, 2005, p. 59-60, grifos nossos)

A cada vez que o capital desenvolve sua capacidade produtiva ele leva o mercado à situação de superprodução e isto, por seu turno, instaura uma crise econômica que "destrói não apenas as mercadorias, como ainda os meios de produção (fábricas, energia, etc.) e também parte da própria força de trabalho (que muda para outras localidades, arranja emprego em outros ofícios ou, mesmo, perece na miséria)" (TONET, LESSA, 2012, p. 65). O próprio prolongamento da crise, a produção parada, a diminuição dos salários e outros fatores acabam fazendo com que a abundância ceda lugar, eventualmente, à carência e o ciclo recomeça até atingir um novo ápice de superprodução que será sucedido por uma nova crise.

Entretanto, o novo crescimento econômico não parte do mesmo ponto inicial: "como o maior sempre engole o menor, ocorre uma crescente concentração do capital, de tal modo que os capitalistas que sobreviveram às crises possuem uma capacidade produtiva cada vez maior" e "controlam um maior volume de capital e de meios de produção" sendo que, dessa maneira, "a retomada do ciclo se dá em um novo patamar que, em poucos anos, desemboca em uma nova crise e nova rodada de concentração e assim sucessivamente" (TONET, LESSA, 2012, p. 65).

De modo geral, a própria situação de crise significa "restrição à pulsão à expansão, e expõe a ineficiência dos ajustes estratégicos antes utilizados para manter em equilíbrio um sistema naturalmente instável e dinâmico, devido à sua constituição estruturalmente antagônica" (PANIAGO, 2012, p. 50).

Com a crise estrutural do capital, agora experimentada desde os anos 1970, a "crise deixou de ser um fenômeno intermitente para se converter no modo permanente de reprodução da sociedade burguesa" e "todas as contradições sociais se intensificam em escala planetária" sendo que "as alienações se elevam a um patamar antes desconhecido" (TONET, 
LESSA, 2012, p. 73). Uma das diferenças desta crise estrutural em face das anteriores está no fato de seu caráter ser global e não apenas local, como veremos adiante, e, ainda, o fato do capital não ter mais como deslocar essa crise de uns países para outros e, por isso mesmo, essa crise "atinge hoje as estruturas mais profundas da sociabilidade capitalista" (TONET, 2009, p. 126).

Para Mészáros, o caráter "novo", por assim dizer, da crise estrutural que enfrentamos desde os anos 1970 está baseado em quatro aspectos. 1) Seu caráter é universal, ou seja, não se refere apenas a uma dimensão particular deste sistema; 2) Sua escala de abrangência é eminentemente global e não circunscrita à alguns países apenas; 3) Trata-se de uma crise que possui uma escala de tempo contínua/permanente e não limitada como todas as outras crises o foram e; 4) Seu desdobramento rastejante, isto é, nem as convulsões mais violentas podem ser excluídas (MÉSZÁROS, 1995, p. 680-681). De modo geral, podemos entender que a crise estrutural possui:

01) seu caráter multidimensional, 02) pluriescalar, 03) sua manifestação territorialmente desigual e espacialmente articulada e, 4) sua problemática determinação coercitiva. A multidimensionalidade da crise estrutural se baseia no fato de que ela não afeta apenas uma dimensão da vida social, mas sim a totalidade desta formação social em seus multifacetados aspectos e determinações. A pluriescalaridade, por sua vez, está no sentido de estender seus efeitos mais dramáticos a todas as escalas: desde a escala do corpo (vejam, por exemplo, os milhões de mortos presente na guerra enquanto estratégia de reprodução dos imperativos expansionistas do capital ou, ainda, podemos pensar nos milhões de indivíduos que sofrem com câncer oriundo do uso intensivo de agrotóxicos praticamente em todos os alimentos, etc.) até a escala global, uma vez que seus efeitos não afetam apenas os países menos desenvolvidos do ponto de vista capitalista. $\mathrm{O}$ caráter territorial desigual se relaciona à manifestação concreta da crise de maneiras diferenciadas em cada território: uns sofrem de modo mais acentuado com as desigualdades do agronegócio e outros, por exemplo, com a dinâmica do mercado imobiliário. Todavia, mesmo tendo territorializações diferenciadas a crise se articula em todos os territórios a partir da lógica de reprodução do capital que organiza o espaço geográfico de modo estruturado e hierárquico. (ROSSI, 2017, p. 102, grifos nossos)

A crise estrutural do capital, deste modo, impacta sobre a totalidade social e em todas as suas relações com as partes que engloba. Uma crise não estrutural, ao contrário, impacta apenas algumas dimensões sociais e não colocam em risco a permanência do próprio sistema enquanto uma "estrutura global". A crise estrutural "coloca em questão a própria existência do complexo global envolvido, postulando sua transcendência e sua troca por algum complexo alternativo" (MÉSZÁROS, 1995, p. 681). Com relação aos limites do capital, uma crise estrutural, se relaciona aos limites últimos da estrutura global. Os limites imediatos do capital, numa crise cíclica, por exemplo, podem ser alterados mediante 1) a modificação de 
algumas partes em questão; 2) uma mudança geral em todo sistema e; 3) uma alteração da relação de uma dimensão com outra dimensão social.

A separação, ou seja, os "defeitos estruturais" entre produção e controle, produção e consumo e produção e circulação, na crise estrutural, assumem "perturbações" cada vez mais problemáticas, de modo que não só o crescimento pode ser rompido, mas também a capacidade de deslocar as contradições que são produzidas e acumuladas pelo próprio sistema. Daí o caráter "explosivo" da crise estrutural, pois as contradições produzidas e acumuladas pelo capital passam a não serem mais administradas dentro da lógica do próprio sistema, mas sim, aumentarem suas dimensões e se tornarem, de fato, extremamente perigosas para o futuro da humanidade. Observemos, pois, que o filósofo húngaro alerta que as contradições do capital nunca foram efetivamente sanadas pelo capital, mas sim, deslocadas, aumentando, com efeito, seu potencial "explosivo" e problemático. O capital, “jamais resolveu nem até a menor de suas contradições" (MÉSZÁROS, 1995, p. 684).

Por isso que o modo "normal" do capital lidar com suas contradições é aumentá-las, acentuá-las e jogá-las para um patamar mais elevado, esse é o sentido de deslocamento. Para onde toda esta dinâmica nos leva? Para nosso autor: "o capital não pode ter outro objetivo que não a na sua própria autorreprodução na qual tudo o mais, da natureza a todas as necessidades e aspirações humanas, deve se subordinar em absoluto" (MÉSZÁROS, 1995, p. 685). A capacidade civilizatória deste sistema social encontra seu fim perante a própria lógica de reprodução expansiva do capital, esbarrando nas necessidades humanas mais básicas. Este sistema de controle estrutural hierárquico do trabalho está em crise porque sua histórica "raison d'être" e sua "justificação" não podem mais ser reinventadas. Dessa maneira, "ao manter milhões na indigência e passando fome, quando os trilhões desperdiçados poderiam alimentá-los mais de cinquenta vezes [...]” (MÉSZÁROS, 1995, p. 685).

A verdadeira questão, com efeito, é o trabalho perante o capital. Este sistema social produz ao mesmo tempo as condições materiais necessárias para o desenvolvimento dos indivíduos sociais e, instantaneamente as nega, chegando a negar as próprias condições materiais perante crises econômicas, políticas e culturais quando implica na sobrevivência desta mesma estrutura de dominação.

Dessa forma, a crise atual é estrutural já que o capital não é "capaz de controlar sua lógica destrutiva, de dar solução aos crescentes problemas sociais e de evitar os impactos desestabilizadores das contradições de sua reprodução ampliada, propagados no interior da própria ordem capitalista" (PANIAGO, 2014, p. 47). 
A única saída para esta crise estrutural é a revolução socialista que envolva os "produtores associados" na reestruturação radical completa deste sistema social por outro completamente novo e superior. De modo geral, a revolução socialista é encarada apenas do seu ponto de vista político e não em seu caráter "multidimensional" e social (MÉSZÁROS, 1995, p. 696). Todavia a conquista do poder político é, apenas, o ponto de partida que revela “as reais dificuldades e contradições dessa transformação” (MÉSZÁROS, 1995, p. 696). Para uma crise estrutural do capital, portanto, a única solução viável é "uma alternativa socialista global” (MÉSZÁROS, 1995, p. 702).

Novamente aqui é preciso reafirmar a extrema importância, para a luta socialista, em não ter ilusões a respeito das políticas sociais, em razão da "dependência do Estado em relação à economia", no sentido de que elas - as políticas sociais, "por mais que possam contribuir para a defesa dos interesses dos trabalhadores, sempre esbarrarão nos limites insuperáveis postos pela reprodução do capital” (TONET, 2015, p. 281).

O capital, retoma o filósofo, é por sua própria natureza incontrolável. Nesse aspecto, investir esforços na tentativa de reformar um sistema sociometabólico incontrolável é uma "aventura muito mais fútil do que o trabalho de Sísifo"” (MÉSZÁROS, p. 1995, p. 713). Na opinião do autor, este fora o erro condenável do movimento parlamentar social-democrata, tentando, através da legislação parlamentar, construir uma "reforma estrutural". Importantíssimo aqui é também notar que o fato do capital ser incontrolável não implica tão somente que ele seja irreformável, mas, igualmente, implica compreender que o capital não “pode compartilhar o poder” com forças que intentem superá-lo (MÉSZÁROS, 1995, p. 716). Enquanto o capital permanecer no controle do processo de reprodução social não há "competição igual entre capital e trabalho", sendo esta uma verdadeira mistificação.

Os representantes do trabalho que tentam preservar um posicionamento crítico e radical “ou são mantidos fora do Parlamento ou são completamente marginalizados no seu interior” (MÉSZÁROS, 1995, p. 717). Um grande desafio prático, neste contexto, é, portanto, não menosprezar ou rejeitar as lutas no âmbito do Parlamento, mas "subordiná-las às lutas

\footnotetext{
${ }^{2}$ Alusão ao mito grego no qual Sísifo - um rei muito astuto - desobedeceu às ordens de Zeus e fora mandado ao mundo dos mortos. Todavia, Sísifo enganou o deus da morte Tânatos e, posteriormente, enganou Hades o deus da terra dos mortos. Zeus, o deus dos deuses, conseguiu capturar Sísifo e o condenou à eternidade a empurrar uma pedra gigantesca ao topo de uma montanha, porém, sempre que a tarefa estava quase terminada a pedra se deslocava e todo o trabalho tinha que ser repetido novamente, ad infinitum.
} 
extraparlamentares" e que as "próprias lutas extraparlamentares adquiram um caráter cada vez mais anticapitalista e antiestatal" (TONET, 2015, p. 294)

A luta do trabalho, dessa forma, precisa assumir o caráter de uma ofensiva, no sentido de assumir conscientemente o objetivo da "negação radical e a transformação positiva do modo de reprodução sociometabólica” (MÉSZÁROS, 1995, p. 723). Uma grande dificuldade, nesta imensa tarefa histórica, é que ao mesmo tempo em que é limitadora é necessário a "ganhar o controle da esfera política” (MÉSZÁROS, 1995, p. 727), mas, tendo claro, que este é um ponto de partida necessário e a essência da transformação socialista é a revolução social, no sentido de superar o controle do capital sobre o trabalho.

É preciso ter sempre em mente que o “capital não é uma força parlamentar" (MÉSZÁROS, 1995, p. 730). Na verdade, o "capital é a força extraparlamentar par excellence que não pode ser politicamente restringida no seu poder de controle sociometabólico" (MÉSZÁROS, 1995, p. 734). Em face de tudo isto que "o poder extraparlamentar do capital só pode ser confrontado pela força e pelo modo de agir extraparlamentares do trabalho" (MÉSZÁROS, 1995, p. 736).

Desse modo, a ação extraparlamentar do trabalho deve: 1) afirmar seus "interesses estratégicos como alternativa sociometabólica" e; 2) o poder político do capital no Parlamento precisa ser "desafiado" a partir "da pressão que as formas de agir extraparlamentares podem exercer sobre o legislativo e o executivo". Por isso mesmo que um "movimento socialista de massa estrategicamente extraparlamentar viável" é uma "precondição vital para se contrapor ao poder massivo extraparlamentar do poder do capital” (MÉSZÁROS, 1995, p. 738).

\section{CONSIDERAÇÕES FINAIS}

Se quisermos, de fato, superar a crise estrutural do capital há que superar este sistema sociometabólico em sua totalidade e isto, por sua vez, recoloca a importância em fazer avançar o trabalho associado que é a base, ou seja, a matriz do socialismo e do comunismo. Por trabalho associado não devemos entender economia solidária, cooperativismo, associativismo etc. Tudo isto não é capaz de romper com o capital.

Por trabalho associado estamos entendendo "uma associação de homens livres, que trabalham com meios de produção coletivos e que conscientemente despendem suas forças de trabalho individuais como uma única força social de trabalho" (MARX, 2013, p 153). O trabalho associado, num movimento socialista eminentemente antiestatal e anticapitalista, 
permitirá fazer avançar um controle universal dos próprios trabalhadores sobre todo o processo produtivo em escala global. Assim, a nova totalidade social que será fundada, terá como momento predominante não mais as relações sociais de produção capitalistas, mas sim, uma forma de trabalho qualitativamente superior que tornará viável o desaparecimento de toda forma de desigualdade social e de exploração do homem pelo homem. Isto será possível, se a humanidade conseguir desempenhar este desafio histórico, pois o trabalho associado não necessita da existência da propriedade privada e de classes sociais antagônicas e irreconciliáveis.

Apenas assim poderemos, então, ter uma orientação geral em cada complexo social que possibilite o atendimento das reais aspirações humanas e não dos interesses "cancerosos e suicidas" (MÉSZÁROS, 1995) da reprodução do capital.

\section{REFERÊNCIAS}

ANDRADE, A. M. Trabalho e Totalidade Social: O Momento Predominante da Reprodução Social na Ontologia de Lukács. Dissertação (Mestrado em Serviço Social) Universidade Federal de Alagoas - UFAL, 123 p. 2011.

LESSA, S. Para compreender a Ontologia de Lukács. 4. ed. São Paulo: Instituto Lukács, 2015.

LUKÁCS, G. Para uma ontologia do ser social - Vol I. São Paulo: Boitempo: 2012.

LUKÁCS, G. Para uma ontologia do ser social - Vol II. São Paulo: Boitempo: 2013.

MARX, K. O capital: crítica da economia política, Livro I: o processo de produção do capital. São Paulo: Boitempo, 2013.

MESZÁROS, I. Beyond Capital: toward a theory of transition. Merlin Press: London, 1995.

PANIAGO, M. C. S. Mészáros e a incontrolabilidade do capital. São Paulo: Instituto Lukács, 2012.

PANIAGO, M. C. S. A crise estrutural e a centralidade das classes sociais. Revista Katál., Florianópolis, v. 17, n. 1, p. 41-49, 2014.

ROSSI, R. Trabalho, Educação e Crise Estrutural do Capital. Geosaberes, Fortaleza, v. 8, n. 14, p. 95-106, 2017.

TONET, I. Educação, Cidadania e Emancipação Humana. Ijuí: Unijuí, 2005.

TONET, I. Expressões Socioculturais da Crise Capitalista na atualidade. In: Conselho Federal de Serviço Social - CFESS; Associação Brasileira de Ensino e Pesquisa em Serviço Social ABEPSS. Serviço Social: Direitos Sociais e Competências Profissionais. Brasília - DF, 2009, p. 124-142. 
TONET, I. Qual Política Social para Qual Emancipação? Revista Ser Social, v. 17, n. 37, p. 279-295, 2015.

TONET, I.; LESSA, S. Proletariado e sujeito revolucionário. São Paulo: Instituto Lukács, 2012. 